\title{
RETRACTED ARTICLE: Alpha particle emissions from Carrara marble specimens crushed in compression and X-ray photoelectron spectroscopy of correlated nuclear transmutations
}

\author{
Alberto Carpinteri · Giuseppe Lacidogna • \\ Oscar Borla
}

Received: 22 January 2014/Accepted: 19 May 2014/Published online: 1 July 2014

(C) Springer Science+Business Media Dordrecht 2014

This article has been withdrawn by the Publisher and the Society in agreement with the Editor-in-Chief due to conflict of interest reasons. In a commitment to scientific integrity we decided to withdraw the article as the editorial process had been compromised.

\footnotetext{
A. Carpinteri · G. Lacidogna · O. Borla ( $\square)$

Department of Structural Geotechnical and Building Engineering, Politecnico di Torino, Corso Duca degli Abruzzi 24, 10129 Turin, Italy

e-mail: oscar.borla@polito.it
} 